\title{
VARIAÇÕES GRÁFICAS EM UM DOCUMENTO DO SÉCULO XVII
}

\author{
Expedito Eloísio XIMENES
}

Universidade Estadual do Ceará (UECE)/Universidade de São Paulo (USP)

Manoel M. SANTIAGO-ALMEIDA

Universidade de São Paulo (USP)

\section{RESUMO}

Neste artigo,o fazemos a descrição do sistema gráfico de um documento do século XVII, mostrando que a representação dos grafemas passava por um processo constante de variação, quando não estava totalmente organizado um sistema ortográfico. O texto é escrito por um padre da Companbia de Jesus, que tinha conhecimento da estrutura da lingua, apresenta uma sintaxe rebuscada, faz, uso de recursos estilísticos como metáforas, expressões latinas e outras marcas da norma padrão, no entanto, apresenta uma grande variação grafemática. Nosso propósito é fazer o levantamento das ocorrências e apresentar algumas interpretações dos usos das variantes gráficas de uma mesma palavra. Elencamos as palavras que são grafadas de forma diferenciada e fizemos algumas interpretações sobre as variações. Embora cronologicamente o texto seja escrito no periodo de predominância da escrita etimológica, há muitas ocorrências da escrita fonética.

\section{ABSTRACT}

This paper presents a description of the graphical system of a seventieth century manuscript pointing out that the graphemes representation faced a constant process of variatin when there were no grammatical rules established to regulate the spelling of words. The text was written by a priest of the Society of Jesus whom had knowledge of the Portuguese language structure. The text presents ornate syntax, and it shows stylistic features like metaphors, Latin expressions and other marks of the standard grammar; however, it presents a large graphematic varietion. Our purpose aims at doing a survey of the occurrences presenting some interpretations of the uses of the variety of one single word. We listed different ways

(C) Revista da ABRALIN, v.16, n.3, p. 503-520, jan./fev./mar./abr. 2017. 
the words are written and we did some interpretations emphasizing that the act of writing at that time was guided basically by the writer's freedom of choice once in the seventieth century there was not any agreement about standard orthography. Although the psendo- etymological pattern was already in use, it is the phonological model based on the recording of graphical variants of a single word, the responsible for producing on some occurrences, differences and difficulties of understanding that really stands out.

\section{PALAVRAS-CHAVE}

Escrita fonética. Escrita pseudoetimológica. Variação gráfica.

\section{KEYWORDS}

Phonetic writing. Pseudo-etymological writing. Graphical variation.

\section{Introdução}

A grafia das palavras é a forma mais concreta de visualização de uma língua, já que a oralidade não reproduz a representação concreta dos grafemas. Por meio da pronúncia, podemos perceber o acento, o ritmo, a entonação, as diferenças que distinguem um fonema do outro, como /ô/ e /ó/, e as variações de um mesmo fonema, como em [ti] e [ $\left.\mathrm{t}_{\mathrm{j}}\right]$ no vocábulo tia, por exemplo, dentre outros elementos que só são perceptíveis na modalidade falada.

Ainda que o sistema ortográfico se baseie também no aspecto fonético para o registro das palavras, não há regularidade. Quando tomamos a letra $h$, por exemplo, em palavras como homem, hoje e hora em que não há unidade sonora atribuída a esse grafema nesse contexto, torna-se confuso para quem está no processo de aprendizagem da modalidade escrita ou para um aprendiz estrangeiro.

Pretendemos, neste artigo, apresentar algumas variações gráficas registradas em um documento do século XVII, que remete a um mesmo fonema. Apresentaremos apenas as variações gráficas de uma mesma 
palavra em que o autor do texto, mesmo com formação em Teologia e com domínio da língua materna, um padre da Companhia de Jesus, não apresenta regularidade quanto às formas gráficas.

A maneira de grafar, aproximando as palavras da sua feição sonora ou do seu étimo, era uma prática comum independentemente do grau de instrução de quem escrevia até, pelo menos, no início do século XX. Em todo o período da história da língua portuguesa, desde o século XIII, reinava uma suposta liberdade de registro ao gosto do escrevente. Somente em 1911 entrou em vigor o acordo ortográfico para uniformizar a grafia. Naquele longo período histórico, a ortografia era uma prática ao gosto de cada um. Conforme Silva (2016, p. 9), "o cidadão escolhia o autor de sua simpatia ou conveniência, sem qualquer obrigação de seguir à risca as normas indicadas pelo escolhido".

O texto de nosso estudo é datado de 26 de março de 1608, conforme está registrado no final do documento. Este período já era considerado a época moderna da língua portuguesa com o retorno ao classicismo, pois já era solidificada uma cultura literária, linguística e gramatical em Portugal, com o desenvolvimento de gramáticas e dicionários. Mesmo assim, é muito recorrente a escrita fonética e as variações de registro de uma mesma palavra, em que, por exemplo, o fonema /s/ aparece registrado com os grafemas $s$ ou $c$, como é o caso de sertão/certão.

Se pensarmos nas mãos que escreveram o texto em análise, eram essas muito hábeis, pois o padre Luís Figueira era um jovem sacerdote missionário da famosa Companhia de Jesus, que veio ao Brasil em missão, tinha formação intelectual em diversas áreas, tendo, posteriormente, escrito uma gramática da língua tupi. É ele o responsável por narrar os fatos, uma espécie de relatório, ao seu superior.

Por se tratar de um texto manuscrito, fizemos uma transcrição conservadora, com poucas interferências, o que denominamos de edição diplomático-interpretativa. Mantivemos do texto matriz: a mesma paragrafação; a mesma translineação; a mesma pontuação e acentuação 
gráfica; a mesma disposição das linhas; a escrita fonética com os diacríticos; o uso de letras maiúsculas ou minúsculas; as junturas e as separações das palavras, dentre outras características. Nossa interferência está restrita ao desenvolvimento das abreviaturas, grifando os acréscimos em itálico e em negrito. Interessa-nos o texto conservador para destacarmos as variações grafemáticas, objeto de estudo a ser observado aqui.

Selecionamos as palavras que, ao longo das 25 páginas do relatório de Luís Figueira, são grafadas de forma variada, embora sejam encontradas muitas outras ocorrências que mereçam um estudo à parte. Analisamos conforme os manuais de gramática histórica e interpretamos o fenômeno, conjecturando sobre as possíveis causas das variações.

\section{O contexto histórico do documento}

O documento de nossa análise intitula-se Relação do Maranhão 1608. É assinado pelo padre Luís Figueira, missionário da Companhia de Jesus que, em 1607, adentrou o território que mais tarde viria a ser o estado do Ceará. Figueira veio juntamente com o seu companheiro de congregação, o padre Francisco Pinto, que era bem mais velho e bom conhecedor da cultura e da língua tupi.

O texto manuscrito a que tivemos acesso encontra-se no ARCHIVUM ROMANUM SOCIETATIS IESU (ARSI) em Roma e nos foi enviado pelo seu diretor. Não nos arriscamos a confirmar que seja o texto autoral, mas há possibilidades de sê-lo dadas as características do tipo de letra, que é uma cursiva com caracteres de uma variante gótica ainda usada no século XVII. O espaço ocupado no papel, o formato das letras, o tamanho, o traçado e o peso, tudo é rigorosamente muito regular, indicando ser do mesmo punho e, no final, a assinatura de Luís Figueira condiz com o tipo de letra do corpo do texto.

A narrativa dos acontecimentos, a descrição de lugares e dos costumes indígenas e o juízo de valor sobre alguns fatos são dispostos 
em 12 fólios escritos no recto e no verso e até a metade do recto do fólio 13, em uma linguagem simples e clara, uma sintaxe rebuscada e estilo agradável, não faltando algumas metáforas e usos da intertextualidade. Os sentimentos expressos diante de fatos tristes e pesados, como a fome sofrida no caminho, a perda de alguns amigos, sobretudo, a descrição da morte do padre Francisco Pinto de forma violenta, são algumas das características do documento. $\mathrm{O}$ autor do relatório ou relação demonstra o domínio da língua portuguesa na modalidade padrão e da língua dos nativos, como é notável a um jovem sacerdote inaciano no século XVII, que mais tarde escreveu uma gramática da língua tupi.

A vinda dos missionários a terras ignotas tinha uma razão muito especial. Naquele início dos anos seiscentistas, a então capitania do Ceará ainda não fora efetivamente ocupada pela coroa portuguesa, já passado mais de um século da chegada dos descobridores ao Brasil. O território que se localizava entre Pernambuco e Maranhão, à época, estava ainda desocupado sem nenhum núcleo administrativo e era assaz vulnerável às invasões de estrangeiros, principalmente dos franceses que já ocupavam o Maranhão e faziam investidas nos limites com o Ceará, nas imediações da serra da Ibiapaba.

Numa primeira tentativa de estabelecer o governo e fundar um núcleo administrativo, Pero Coelho de Sousa esteve em 1603, em terras cearenses, mas foi frustrada sua tentativa de estabelecer núcleo ocupacional. Após gerar um conflito com os índios que habitavam a ribeira do Jaguaribe e o sopé da serra da Ibiapaba, Pero Coelho retorna sem sucesso, levando vários índios como cativos e deixando espalhado o medo aos nativos e a inimizade dentre esses e os brancos. Daí a necessidade de uma parceria da coroa portuguesa com a Companhia de Jesus, a fim e que essa enviasse dois padres para apaziguar os ânimos dos indígenas, evangelizando-os conforme as determinações religiosas e tentando alcançar o Maranhão, para intimidar a presença dos franceses. 
A missão dos padres tinha dois objetivos bem claros, expressos no primeiro parágrafo do documento: catequizar os índios e chegar ao Maranhão para expulsar os franceses que eram empecilhos à coroa portuguesa, conforme diz Figueira.

No mês de janeiro de 607 por ordem do padre Fernão Cardim provincial desta província nós partimos para a missão do Maranhão, o padre Francisco Pinto e eu com obra de sessenta índios, com intenção de pregar o evangelho àquela desamparada gentilidade, e fazermos com que se lançassem da parte dos portugueses, deitando de si os franceses corsários que lá residem (Fl. 1r, L.511). ${ }^{1}$

O percurso dos padres é estabelecido desde a chegada, no dia 02 de fevereiro de 1607, quando adentram ao Ceará na foz do rio Jaguaribe, vindos de Pernambuco em um pequeno barco. Seguem pelo litoral até a altura da atual cidade de Fortaleza, em que registram o encontro com alguns índios às margens do rio Ceará ${ }^{2}$. Seguem pelo litoral oeste alcançando uma enseada a que chamam de Pará, nas proximidades, provavelmente, da atual cidade de Paracuru, situada a $84 \mathrm{Km}$ e Fortaleza. Depois adentram o sertão, atingindo a serra dos Corvos, atualmente, Uruburetama. Na descida dessa serra, atravessam o rio Aracatiaçu, a que denominam Aracategi, e seguem para o norte até a serra da Ibiapaba. Hospedam-se em uma pequena e pobre aldeia, depois sobem mais a serra para outra aldeia maior. Após alguns meses tentando estabelecer contato com os tapuias que habitavam o Maranhão, esses atacam a aldeia em um determinado dia e assassinam o padre Pinto, quebrando-lhe o crânio. Após as exéquias e o sepultamento do amigo, Figueira desce para

\footnotetext{
${ }^{1}$ Estamos citando a edição diplomático-interpretativa que realizamos, que não está publicada, embora já haja outras edições publicadas.

${ }^{2} \mathrm{O}$ rio Ceará deságua no mar, onde hoje é conhecido por Barra do Ceará, um bairro na zona oeste de Fortaleza.
} 
o litoral norte, para as imediações, talvez, da atual cidade de Camocim ou Granja. Lá fica um período numa pequena aldeia liderada pelo seu principal, Cobra Azul, com quem não se relaciona muito bem. Regressa para o rio Ceará, e toma um barco para Natal, depois Pernumbuco.

$\mathrm{O}$ ano de 1607 registra a chegada dos missionários ao Ceará, em 02 de fevereiro. No dia 02 de março, chegam ao Pará, após passarem pelo rio Ceará. No sábado de aleluia atravessam o rio Aracatiaçu, mais ou menos em fins de março ou em abril, quando celebram a páscoa. Em setembro encontram-se na serra da Ibiapaba, quando Figueira fala de um cometa de calda muito longa que aparecia no céu. No ano seguinte de 1608, após a morte de Francisco Pinto, Luiz Figueira desce para o litoral, passa ali vários meses, faz plantações de milho, mas o inverno foi fraco. O que se chama inverno no Ceará é a estação de chuvas que geralmente dura de janeiro a maio. Ali ele permaneceu se preparando para regressar. No dia 19 de agosto ele está em uma aldeia próxima ao rio Ceará, quando recebe uma carta do padre Gaspar de Samperes, dizendo que o barco para seu retorno estava no porto. A Relação do Maranhão é datada de 26 de março de 1608, logicamente não é a data correta. Deve ter havido um erro, um lapso no momento do registro da escritura. $\mathrm{Na}$ verdade, a data de 1608 aparece duas vezes, tanto no início quanto no fim do texto. Poderia ter sido escrita antes da volta de Figueira, quando ela ainda estava no Ceará? Tudo indica que não, pois apesar de não ter a data tópica no documento, os indícios do texto são claros. As marcas linguísticas expressas por meio das formas dêiticas e das referenciações apontam que ele se encontrava em algum ponto a leste do Ceará. Seria Natal, para onde ele se destinou inicialmente, Recife ou Salvador?

$\mathrm{Na}$ passagem abaixo, diz Figueira que chegou a uma aldeia a vinte e cinco léguas além do Jaguaribe. O rio Jaguaribe fica a leste do Ceará, quase na divisa com Rio Grande do Norte, ele havia chegado além do Jaguaribe, ou seja, estava falando de um local situado ao leste do Ceará, à margem direita do Jaguaribe, fazendo referência para frente, para além, isto é, mais para o oeste, onde se situa o rio Ceará. 
Chegamos à outra aldeia que está junto ao rio chamado Ceará, vinte e cinco léguas além de Jaguaribe. Receberam-nos com festas, caminhos feitos, emboscadas, tamboris etc.

A Relação do Maranhão é quase um diário de viagem, com um propósito muito especial: dar conta de todo o processo de evangelização e descrever a cultura dos povos evangelizados aos superiores da Companhia. O gênero relação é na verdade um relatório que todo jesuíta era obrigado a escrever para testar os fatos vividos e assim também fortalecer os irmãos que se encontravam em outras partes do mundo.

Esse documento é de muito valor histórico e linguístico para o Brasil, principalmente para o Ceará, pois marca o princípio da historiografia cearense. Dá conta do embrião da capitania, das tribos indígenas que existiam, seus costumes e crenças, além de apontar para a realidade daquele momento. As questões climáticas que já eram irregulares, um ano de inverno pesado, com enchentes dos rios e muita lama no caminho quando os religiosos chegam; o ano anterior e o posterior são marcados pelas secas e a falta de alimentos. O modo de viver e de comer dos índios; o cultivo da mandioca para diversos produtos, destacando a farinha; o plantio de milho, feijão, favas e abóboras que ainda hoje se preservam na agricultura de subsistência em todo o sertão cearense.

Enfim, o relato dos jesuítas é por demais importante para se conhecer o Ceará e seu processo de constituição como a identidade do cearense. Aqui aliamos ao texto os valores histórico-culturais e linguísticofilológicos, pois por meio da língua, do seu léxico e das formas de referenciação podemos ter um entendimento amplo dos fatos deste pedaço de mundo, naquele pedaço de tempo flagrado que ainda hoje mantém traços semelhantes, demonstrando que o passado nunca é tão superado, sempre deixa marcas, quando não, apenas continua disfarçado em um presente, às vezes, melhorado, mas nem sempre. 


\section{A ortografia da língua portuguesa}

Os compêndios de gramática histórica abordam a temática da ortografia portuguesa, apresentando algumas etapas de estabelecimento e de seu predomínio. As duas primeiras etapas são marcadas, mais ou menos, pela arbitrariedade e pelo gosto pessoal dos escribas, até se constituir, por meio de acordo convencional, aprovado por lei, na fixação de normas que passaram a reger o modo de grafar do idioma português. Apesar das reformas submetidas, o nosso vernáculo se estabeleceu quanto à ortografia em princípios do século XX.

Nunes (1989) divide a história da ortografia portuguesa em dois períodos: o fonético e o pseudoetimológico. O período fonético começa nos primórdios da formação da língua e se estende até o século XVI, coincidindo com o seu período arcaico. Nesta etapa da ortografia, sobressaem-se os sons representados por meio de letras que elas realmente representam.

Segundo Pereira (1932), o sistema fonético consiste em escrever como se pronuncia, fazendo com que a palavra escrita seja imagem da palavra falada. Contudo, como há uma grande variação na maneira de falar de cada indivíduo, como poderia se ter uma uniformidade na grafia já que esta pretende representar os sons da fala? O resultado é um sincretismo na escrita como se refere o autor:

Este systema, tão preconizado pelos phoneticistas, não offerece, comtudo, base uniforme para uma reforma ortographica, vista a grande variedade da pronuncia, de região para região e de século para século. Sendo nelle a palavra escripta a imagem exacta da palavra fallada, a mudança constante da pronuncia determinaria a constante mudança de sua representação. (PEREIRA, 1932, p. 102). 
Para Teyssier (1997), este sistema apesar das incoerências e imprecisões parece mais regular e fonético do que aquele que o substituiu posteriormente.

Embora o sistema fonético refletisse maior coerência e fidelidade ao representar os grafemas conforme sua identidade sonora, percebese que há muito de arbitrário nele, pois há várias formas de grafemas para um mesmo fonema, o que revela a vontade de cada escrevente. "Também os mesmos sons eram representados por caracteres diferentes quer se tratasse de vogais, quer de consoantes” (NUNES, 1989:193).

Assim, por exemplo, o fonema vocálico /i/ era representado por vários grafemas sem nenhuma norma de escolha: ora pela letra $i$, ora pelas letras $y, j$ e $h$, sendo que esta última ocorrência se dava quando semivogal. Temos os registros seguintes: mais, assi, assy, fruyto, mjnas, sabham. Podemos ver, portanto, que não há critério de uso de uma letra por outra; as letras $i$ e $y$ podem ser empregadas no início, no meio e no final de palavras; o $j$ substitui o $i$, sem nenhuma razão fonética. Talvez por não haver ainda estabilidade daquela letra no alfabeto, já que ela não existia na língua latina, sendo introduzida só posteriormente nas línguas românicas. O caso do $h$, em substituição a semivogal $i$, denota certa incoerência do sistema, já que tal letra não representa som algum, como também não há razão etimológica nos casos citados.

Com base em alguns autores como Nunes (1989), Coutinho (1976), Williams (1961), Melo (1975) e Huber (2006), sintetizamos e apresentamos as características da ortografia do período fonético de nossa língua.

As vogais se apresentam de forma dobrada para indicar, às vezes, segundo Huber (1933), a pronúncia aberta, como segue:

$$
\begin{gathered}
\text { aa }=\text { a ataa }>\text { atá }>\text { até } \\
\text { ee }=\text { e quaees }>\text { quaaes }>\text { quaes }>\text { quais } \\
\text { ii, } \mathrm{ij}, \mathrm{ji}=\mathrm{i} \text { imijgo ou iimigo }>\text { imigo }>\text { inimigo } \\
\text { oo }=\text { o dooe }>\text { doe } \\
\text { uu }=\mathrm{u}
\end{gathered}
$$


Coutinho (1976) acrescenta que as vogais dobradas ocorrem por queda da consoante sonora medial latina na mudança para o português, ademais para indicar ainda a vogal tônica. Ocorrendo nesses casos o fenômeno da crase, como resultado de mudança histórica.

$$
\begin{gathered}
\text { aa }=\text { a mala }>\text { maa }>\text { má } \\
\text { ee }=\text { e sedere }>\text { seer }>\text { ser } \\
\text { oo }=\text { o colore }>\text { coor }>\text { cor } \\
\text { uu }=\text { u nudu }>\text { nuu }>\text { nu }
\end{gathered}
$$

As vogais nasais poderiam ser representadas por um $m$, $n$, til $(\sim)$ que, segundo Huber, é o emprego mais vulgar $\tilde{a}, \tilde{e}, \tilde{\imath}, \tilde{o}, \tilde{u}:$ irmãa, cẽa, frìs, bõa, ũa, üu; e ainda por dois acentos (" ): omrra, omde, canbho, senpre, mááos, oméés.

No tocante ao emprego das consoantes, há também muitas variações e confusões. Não muito raro há substituições, emprego duplo, acréscimo e/ou ausência delas, conforme se segue.

A letra $b$ era substituída pela letra $v$ em: aber = haver, nota-se a ausência do grafema $h$ na primeira ocorrência. Diz Huber que o $b$ entre vogais era pronunciado com o som de $v$. O $b$ tem ainda o valor de $b h=b i$ sabham = sabiam.

A letra $c$, com valor fricativo $c$, aparece empregada antes de $e$ e $i$ : çeo, graçia antes de $o$ e $u$ : particon $=$ partiçon, cunucuda $=$ cunucuda, $\varsigma=₹:$ donçela $=$ donzela. Era também substituída por qu: cinquo, acerqua, vaqua. Em outros casos, substituía qu: pecena = pequena.

A letra $f$ muito frequentemente tinha uso dobrado no início e no interior da palavra: ffé, fficar, deffendeu.

A letra $g$ com o valor velar $/ \mathrm{g} /$ aparece antes de $e$ e $i$ : aponge $=$ apougue, Agiar $=$ Aguiar, alge $=$ algue $=$ alguém. Antes de $e$ e $i:$ oge $=o j e$, antes de $a$, o, $u:$ sega $=$ seja, ango $=$ anjo, Gurge $=$ Gurje; $g i$ antes de $a, o=j$ agia $=$ aja, segia $=$ seja; gu antes de e, i, a, o: guiar, Guabriel. Usava-se também o digrama gu: limguoa, augua. 
A letra $h$ aparece no início de palavras como marca etimológica: homẽes. É omitida em palavras em que deveria constar: aver, omildade; ocorre o contrário em palavras que não deveria: huum, hũua, bũu, hi; era empregado por analogia a outras palavras latinas: hordenar, indica vogal aberta em: he, hi, hir, separa as vogais em hiatos no meio das palavras: cahir, sahir, parece representar o som nasal $\tilde{\imath}$ : cambo $=$ camĩo $=$ caminho.

A letra $j$ indicava-se por $g$ antes de $a$ e $o$ : mangar = manjar; aleigom $=$ aleijom $=$ aleijão; por $j$ escrito $i$ ou $y:$ aya $=$ baja, suyo $=$ sujo, ou $e=$ boje; por gi agia $=$ baja .

A letra laparece dobrada no início de palavras: llãa, no final e antes de consoantes: mortall, malldade, castello, ella; entre vogais representava o fonema $/ \lambda /=l h$.

O fonema palatal lateral $/ \lambda /=l h$ e o palatal nasal $/ \mathrm{y} /=n h$ foram representados por li e $n i$, somente $l$ ou ll e $n$ : filia, molier, tenio, conocença; depois th e $n h$.

A letra $m$ seguida de consoante nasalava a vogal anterior; era empregada antes de alveolar ou dental: emsinar, homrrada; era dobrada quando precedida de vogal nasal: emmendar, commungar.

A letra $n$ era usada antes de $p$ e $b$ e nasalava a vogal anterior: limpo, anbos; $n=n b:$ vena $=$ venha, seno $=$ senhor, $n n=n b:$ venna $=$ venha, aranna $=$ aranha.

A letra $p$ aparece entre vogais nasais sem valor fonético: dãpno, solẽpnemente = solenemente. Há inserção do $p$ em formas do verbo escrever: escrepver. Segundo Williams (1961), esta inserção do $p$ denominado de intruso é para preservar o som de ambas as vogais.

A letra $q$ ocorre antes de $e$ e $\tilde{e}$, e o grupo $q u$ antes de $a$ e $o$ com o valor de $c$ quada $=$ cada, riquo $=$ rico, cinquo $=$ cinco, Francisquo $=$ Francisco, o qu também equivale a $q$ simples: aqela $=$ aquela.

A letra $r$ dobrada aparece no início de palavra e, às vezes, ocorre $r$ simples no meio da palavra por $r$ dobrado: rrainha, rrogo $=$ rogo, tera $=$ terra, recore $=$ recorre, barete $=$ barrete. Ocorre também antes e depois de le de $n$, depois de $s$ : Carrlos, honrra. 
A letra $s$ ocorre como substituta da letra $c$ ou $\ell$ sima $=$ cima, composisam = composição; aparece no início sem prótese da vogal $e$ apoio no grupo consonantal impróprio st: stado, scrito, star. Às vezes, quando simples, era empregado com valor duplo: posso = poso, e vice-versa: $c a s s a d o=c a s a d o$, messa=mesa; no meio de palavras era representado simples ou dobrado: servisse, misa, coussas; quando tinha o som de z era duplo no início e meio de palavras: leprosso, ssabede.

Nos documentos notariais e demais documentos oficiais da administração pública produzidos em todo o período da história da língua portuguesa, até início do século XX, são muito recorrentes as formas apresentadas acima, fato que veio a se modificar com a vigência do acordo ortográfico de 1911, pois dos séculos XVI ao século XX “em Portugal e no Brasil a escrita praticada era fundamentada na etimologia (procurava-se a raiz latina ou grega para escrever as palavras), não havendo uma ortografia oficial" (SILVA, 2016, p. 9).

O texto que analisamos traz bastante desses usos, não obstante o conhecimento linguístico de quem o escreveu. Além das muitas formas variantes de uma mesma palavra, objeto de nosso estudo aqui. Apresentamos as ocorrências de registro e nossas interferências interpretativas dos fenômenos.

O fonema / s / apresenta as formas grafemáticas variantes $s$ e c: sertão/ certão; ç e ss em roça/ rossa; cabasso/ cabaços, conforme era prática. Trata-se do mesmo fonema e as possibilidades de manifestações gráficas de sua representação que indica ficar ao gosto do uso, pois não há um sistema que estabeleça um limite.

$\mathrm{O}$ fonema /z/ é representado grafematicamente com z ou $s$ em Almazonas, almasonas, Amazonas; o mesmo corre em fraqueza, fraquesa. É coerente a grafia $\%$ pois representa o fonema, mas para que pensar em coerência nesse período? Chama-se a atenção dos dois casos do $l$ epentético em almazonas, talvez para diferenciar as entidades mitológicas que habitavam a região do nome do rio Amazonas ou simplesmente porque predomina o gosto. 
A representação gráfica do fonema /i/ ocorre com o grafema $i$, variando para $y$ e $j$ de maneira muito frequente, pois apresentam a mesma feição fonética e, por não haver uma convenção, os três concorrem em qualquer posição na palavra, pela liberdade do autor, estética, dúvida na hora de escrever? Observamos as ocorrências em Ybiapaba/Ibiapaba,ygreja/igreja, yndio/ indio, yr/ir, tapuyas/tapuias, enterrey/ enterrei, assil assy, ido/yda, infinidade/jnfinidade.

As vogais altas /i/ e / $/$ / alternam-se em noite/noute talvez pelo lugar da língua na boca na realização dessas vogais já que elas são aproximadas. Apesar do traço de anterioridade e posterioridade, uma ser classificada como posterior e a outra anterior, distanciam-se, no entanto, há possibilidade de substituição. As variações de uma vogal alta para uma média alta também ocorrem, caracterizando um ligeiro abaixamento do /u/ para /o/ em seus/seos, Deus/Deos, Jaguaribe/Jagoaribe, subir/sobir, fugião/fogião. A realização dessas vogais é muito próxima e ambas são posteriores, além disso, há uma motivação etimológica em Deos/Deus, pelo acusativo plural. Na palavra Jaguaribe poder-se-ia aventar a hipótese de essa palavra ser de origem tupi, assim como em Ibiapaba/Ybiapaba, mas não se sustenta nenhuma conjectura sobre isso, já que a variação ocorre largamente em contexto de palavras de origem latina.

Há também o alteamento ou alçamento da vogal medial baixa /e/, que alterna sua representação com a vogal alta /i/ em melhor/milhor e vice-versa quais/quaes. A vogal média alta anterior varia para a vogal média alta posterior pela sua aproximação no trato vocal pello/pella, pollas/pollos. Destaca-se aqui também a consoante lateral / //dobrada que era comum no modelo de escrita pseudoetimológico.

Em outras ocorrências, percebemos também o fenômeno de alteamento da vogal nasal baixa central para a vogal média alta talvez motivada pela nasalidade, nas variações de manham/manhã/menhã menham. Esta forma era usada em textos clássicos do século XVI e vale salientar que ainda é ouvida a sua pronúncia no interior do Ceará 
entre pessoas de idade mais avançada. A vogal final aparece ora com o diacrítico marcando a nasalidade ora com o $m$ desenvolvido com o mesmo fim.

A forma de representação de qu por $c$ em qualidade/calidade ou o inverso em brancos/branquos é descrito pelos gramáticos como forma corrente no período. O primeiro fato citado ainda é corrente na fala atual tanto de crianças quanto de pessoas idosas e de pouca escolaridade nas palavras quantidade, qualidade, quando em que se ouvem cantidade calidade, cando etc. Na palavra branco/branquo assim como cinco/ cinquo não é perceptível a realização de traços distintivos, apenas dos grafemas, percebendo-se aqui os resquícios etimológicos ou pseudoetimológicos do latim.

A representação do fonema /3/ pelos grafemas $g$ e $j$ é um caso que ainda gera dúvidas no ato de escrever, pois não há traço distintivo a não ser por razões etimológicas ou convencionais. Esse registro é muito comum na prática da escrita hodierna. Observamos que além dessa variante há o uso da vogal baixa / a/ pela média baixa /e/na palavra salvages, salvajes, salvagens por selvagens.

Destacamos outras ocorrências de representação fonética em que o sinal diacrítico $(\sim)$ grafado sobre a letra apenas indica o traço de nasalidade da vogal, em mãdioca/mandioca, mãcebo/mancebo, também/tãbem, cosigo/cõsigo/comsigo, aõde/aonde, cãtavaõ / cantar mostram alguns exemplos de usos muito frequentes do texto que é recheado desses fatos.

Algumas ocorrências da escrita pseudoetimológica aparecem também, como consoantes geminadas ll e $p p$, relíquias/relliquias, apparelhando/aparelhando, e o grupo gn, assignalou/assinalou.

Todas estas formas gráficas estão no texto que reflete o contexto histórico da língua no século XVII no quesito grafia, marcado pela liberdade de escolha e falta de um sistema unificador da escrita. O texto também reflete muitas outras particularidades linguísticas, históricas e culturais da sociedade portuguesa, sobretudo as ideologias referentes 
aos nativos e os seus comportamentos, mas o que é foco neste artigo é a variação das formas de grafar uma mesma palavra.

\section{Considerações}

Todo texto reflete os vestígios do seu tempo quer sejam as relações culturais e crenças de uma sociedade, de um grupo específico, de uma irmandade ou de um autor, quer sejam das manifestações da língua escrita com as idiossincrasias e seus usos. Neste estudo, editamos um manuscrito do início do século XVII perpassado de ideologias e de informações históricas, religiosas, convicções, avaliações e juízos de valor. Mas também repleto de formas linguísticas que nos permitem conhecer a história do idioma português.

A grafia das palavras é uma forma de conhecimento da história da língua, pois grafar é a maneira primeira de mostrar a feição de uma língua, muito embora a ortografia seja um quesito à parte ao sistema linguístico, pois pode modificar-se a qualquer momento por meio de um projeto de lei sem que prejudique a sociabilidade inerente às línguas.

Por ser uma parte externa das línguas e não afetar diretamente ao sistema, a ortografia geralmente não é estudada e pouco contemplada nos manuais didáticos e gramáticas, no entanto, uma averiguação mais aprofundada em suas manifestações, possibilita uma compreensão mais ampla sobre a história de um idioma, pois demonstra também uma historicidade. Tudo tem história, tem transformação e mudança. A língua é um conjunto de formas pelas quais as pessoas expressam ideias, identidades, predomínio sobre os outros.

O sistema ortográfico vigente nos primórdios da língua portuguesa reflete as condições sócio-históricas e culturais dos usuários naquele momento que ainda não tinham uma autonomia de unificar uma escrita, mas se expressavam como tinham condições e transmitiam as informações e ideologias. No sistema pseudoetimológico já há outra manifestação de refinamento intelectual quando há uma tentativa 
de retorno a uma época clássica da humanidade. Reflete o desejo de aprimoramento pela herança dos antepassados por meio de uma escrita que os imitava. No entanto, não houve adesão de todos os que faziam usos da escrita, pois o modelo fonético sempre predominou ao lado do etimológico.

Com a consciência de que língua é uma questão política que se impõe por um desejo dos que governam, foi necessária uma lei específica para unificar a grafia. Com essa consciência, também se reconhece a força de uma língua como instrumento de integração de uma sociedade. O século XX é o marco desse momento em que intelectuais e autoridades políticas estabelecem o primeiro acordo ortográfico da língua portuguesa. Mais uma vez não teve a adesão de todos os lusófonos e outras tentativas não conseguiram fortalecer e unir todas as grafias. Isso demonstra que o aspecto ortografia não interfere tão essencialmente no poder que uma língua exerce, pois mesmo com grafias diferenciadas, o idioma português mantém seu papel de integração entre as nações. No momento atual, o último acordo estabelecido está em fase de implantação entre as oitos nações lusófonas, mas ainda desigual e mantendo diferenciações, sem que a língua deixe de ser o que ela é.

Neste estudo, analisamos um texto de 25 páginas escrito nos primórdios do século XVII e percebemos quanta instabilidade há. Imaginemos toda a produção escrita ao longo de tantos séculos de história da língua portuguesa, quantas diferenças, tantas variedades gráficas, que provavelmente, gerem estranhamentos e dificuldades de compreensão, sem jamais prejudicar a estabilidade do sistema. O que queremos afirmar é que a ortografia é uma parte da língua que contribui para sua identidade, mas não é a espinha dorsal dessa, pois poderá se modificar quando um decreto de lei for assinado e os meios de comunicação e a escola aceitarem e passarem a divulgar a nova realidade. 


\section{Referências}

COUTINHO, Ismael de Lima. Pontos de gramática histórica. 7.ed. Rio de Janeiro: Ao Livro Técnico, 1976.

HUBER, Joseph. Gramática do português antigo. 2.ed. Lisboa: Fundação Calouste Gulbenkian, 2006.

MELO, Gladstone Chaves. Iniciação à filologia e à linguística portuguesa. 5.ed. Rio de Janeiro: Livraria Acadêmica, 1975.

NUNES, Joaquim José. Compêndio de gramática histórica portuguesa. 9.ed. Lisboa: Clássica, 1989.

PEREIRA, Eduardo Carlos. Gramática histórica. 7.ed. São Paulo: Cia. Ed. Nacional, 1932.

SILVA, José Pereira da. Ortografia do português do século XVI a 2016. Rio de Janeiro: edição do autor, 2016.

TEYSSIER, Paul. História da língua portuguesa. Tradução de Celso Cunha. São Paulo: Martins Fontes, 1997.

WILLIAMS, Edwin B. Do latim ao português. Tradução de Antônio Houaiss. Rio de Janeiro: Instituto Nacional do Livro, 1961.

Recebido em 10/10/2016 e aceito em 06/12/2016 